\title{
Addressing Tobacco in Managed Care conference
}

The Addressing Tobacco in Managed Care conference is jointly sponsored by the American Association of Health Plans (AAHP) and our partners in the Addressing Tobacco in Managed Care National Technical Assistance Office, the Prudential Center for Health Care Research and Health Alliance Plan, and the Alliance of Community Health Plans, formerly known as the HMO Group. The conference is supported by educational grants from the Robert Wood Johnson Foundation (RWJF), the Agency for Healthcare Research and Quality (formerly the Agency for Health Care Policy and Research), the National Cancer Institute, and the Centers for Disease Control and Prevention. We would like to thank them publicly and personally for their continued support, as without it we would never be able to offer the extensive program on tobacco cessation and control. We would also like to recognise and thank the staff of the Prudential Center for Health Care Research for their extensive work in coordinating the conference logistics, in particular Carol McPhillips-Tangum and Linda Schuessler. In addition, Barbara Lardy, Craig Carlson, and Danielle Skripak of AAHP have worked over the past 18 months on the Addressing Tobacco in Managed Care program and also deserve recognition.

Since the first surgeon general's report in 1964 addressing tobacco use and smoking in the United States, two million Americans have not died from smoking attributable diseases as a result of the decision to either not start or to stop smoking. The success of massive public health education campaigns and consistent visibility of the damaging effects of tobacco use have made the public much wiser and, to some degree, healthier. The numerous lawsuits now before the tobacco companies, even though not all are won in favour of the patient, have served to raise the consciousness of the ill effects of tobacco use. Many public health practitioners have used their effective programs as models to change behaviour and to promote wellness.

The 1998 surgeon general's report outlines specific facts about cigarette smoking and the impact on morbidity and mortality in certain populations, particularly African Americans, Hispanics, Native Americans, and Pacific Islanders. Cigarette smoking is a major cause of morbidity and mortality in each of these four populations studied in the report. The surgeon general, David Satcher, has urged health care organisations and providers to do a better job of ending the disparities in health care and has called for educating, motivating, and mobilising communities to improve the health of our country. This conference will address these important issues.

At the core of this programming is the RWJF and AAHP's Addressing Tobacco in Managed Care National Technical Assistance Program. The mission of the program is to advance the integration of tobacco cessation into routine health care by increasing the number and quality of tobacco control initiatives within managed care organisations. This program seeks to build upon and expand health plans' existing efforts and to encourage a comprehensive tobacco treatment program through the use of evidence based approaches to treating smokers.

Recent surveys reveal that $75 \%$ of all health plans have some type of tobacco control effort underway, and those programs continue to improve and expand. In addition, since health plans now enroll approximately 160 million individuals in the United States, both in health maintenance (HMO) and preferred provider organisation (PPO) models, as well as a growing number of Medicare and Medicaid recipients, these effective programs can have an impact on large populations in need. To date, some of the accomplishments of the program, in addition to our national conference, include regional and corporate training efforts, a variety of presentations at other national health care meetings, articles in national publications, a newsletter, annotated bibliographies which categorise relevant research and resources on tobacco treatment, an electronic resource centre and web site, a listserv to open lines of communication in the field, and the annual awards program.

I would like to take a moment to recognise the 1998 Managed Care Achievements in Tobacco Control award winners. (A full description of the 1998 Managed Care Achievements in Tobacco Control award initiatives may be found in Tobacco Control 1998;7(suppl):S55-8. Descriptions of the 1999 award winners, announced in October 1999 , are described on page $i 76$ of this issue.) In the Adult Tobacco Control Initiative category, first place was awarded to Group Health Cooperative of Puget Sound and second place to Kaiser Permanente Northwest. In the Youth/Adolescent Tobacco Control Initiative category, Kaiser Permanente Northeast received the first place award and second place went to Allina Health System. In the Private/Public Partnership in Tobacco Control category, first place went to Blue Cross and Blue Shield of Minnesota. In the Tobacco Control in Special Populations category, Healthsource Maine received first place honours. Several of the 1998 award winners will share their programs and experiences during the conference.

This conference has been designed to stimulate and expand successful efforts in tobacco cessation throughout the managed care system. We encourage and applaud these notable efforts.

Vice President, Medical Affairs

CARMELLA BOCCHINO

American Association of Health Plans

$112920^{\text {th }}$ Street, $N W$

Washington, DC 20036, USA;

cbocchino@aahp.org 